\title{
Nîmes
}

103 , route de Beaucaire

\section{Marie-Laure Hervé}

\section{(2) OpenEdition}

1 Journals

Édition électronique

URL : http://journals.openedition.org/adlfi/11745

ISSN : 2114-0502

Éditeur

Ministère de la culture

Référence électronique

Marie-Laure Hervé, " Nîmes », ADLFI. Archéologie de la France - Informations [En ligne], LanguedocRoussillon, mis en ligne le 01 mars 2004, consulté le 21 avril 2019. URL : http:// journals.openedition.org/adlfi/11745

Ce document a été généré automatiquement le 21 avril 2019.

(c) Ministère de la Culture et de la Communication, CNRS 


\title{
Nîmes
}

\author{
103 , route de Beaucaire
}

\section{Marie-Laure Hervé}

Date de l'opération : 1995 (SD)

Inventeur(s) : Hervé Marie-Laure (AFAN)

1 Plan général des opérations extra muros de Nîmes (Fig. n³ : Plan général des principales opérations rurales (1991-1998)).

2 En préalable à l'établissement d'une construction venant remplacer une station-service, une expertise archéologique a été réalisée dans la parcelle CX-499, CX-500 qui aurait livré en 1931 les restes d'un monument funéraire (Espérandieu, Emile. 1932. ) [ (Fig. n¹ : Plan de localisation des opérations des 74-76, 81, 103, 113, route de Beaucaire sur fond cadastral), (Fig. $\mathrm{n}^{\circ} 2$ : Plan de détail des vestiges du 103, route de Beaucaire)]. Cette dernière jouxte au sud la route de Beaucaire et se situe à environ 1,2 km de l'enceinte augustéenne.

3 Compte tenu de l'emprise du nouveau bâtiment et des destructions antérieures (cuves de carburant), l'étendue de la parcelle (1 $803 \mathrm{~m} 2$ ) n'a pu être explorée que sur une surface de $335 \mathrm{~m} 2$. Le délai imparti à l'opération a seulement permis l'observation superficielle et le relevé des faits archéologiques mis au jour dans de petits décapages.

Un premier secteur («secteur sud») a livré trois sépultures probables et deux constructions antiques (Fiches, Jean-Luc (dir.); Veyrac, Alain (dir.). 1996.). L'une des tombes est probablement une incinération (fosse d'un mètre de côté) : elle se trouvait accompagnée à l'extérieur de la fosse par le dépôt d'une cruche. Les deux autres tombes sont probablement des inhumations. Deux constructions partiellement conservées ont également été dégagées: la mieux conservée dessine un rectangle $(2,70 \mathrm{~m} \times 1,60 \mathrm{~m})$ constitué par un mur d'environ $0,30 \mathrm{~m}$ de large. L'absence de fouille n'a pas permis l'identification de ces constructions : sépultures, ustrina, bases de mausolées?

Le second secteur (« secteur nord ») a livré des structures linéaires (fossés ?) et de petites fosses (fosses de calage de poteau ou de plantation ?) qui n'ont pu être datées. 


\section{BIBLIOGRAPHIE}

Espérandieu, Émile. 1932 : « Nouvelles diverses », Le vieux Nîmes, 3, 38 p.

Fiches, Jean-Luc (dir.)Veyrac, Alain (dir.). 1996 : Nîmes, Paris, Académie des inscriptions et BellesLettres, coll. « Carte archéologique de la Gaule », 30-1, Pré-inventaire archéologique, 634 p., 31 p. de pl.

\section{ANNEXES}

Fig. $\mathrm{n}^{\circ} 1$ : Plan de localisation des opérations des $74-76,81,103,113$, route de Beaucaire sur fond cadastral

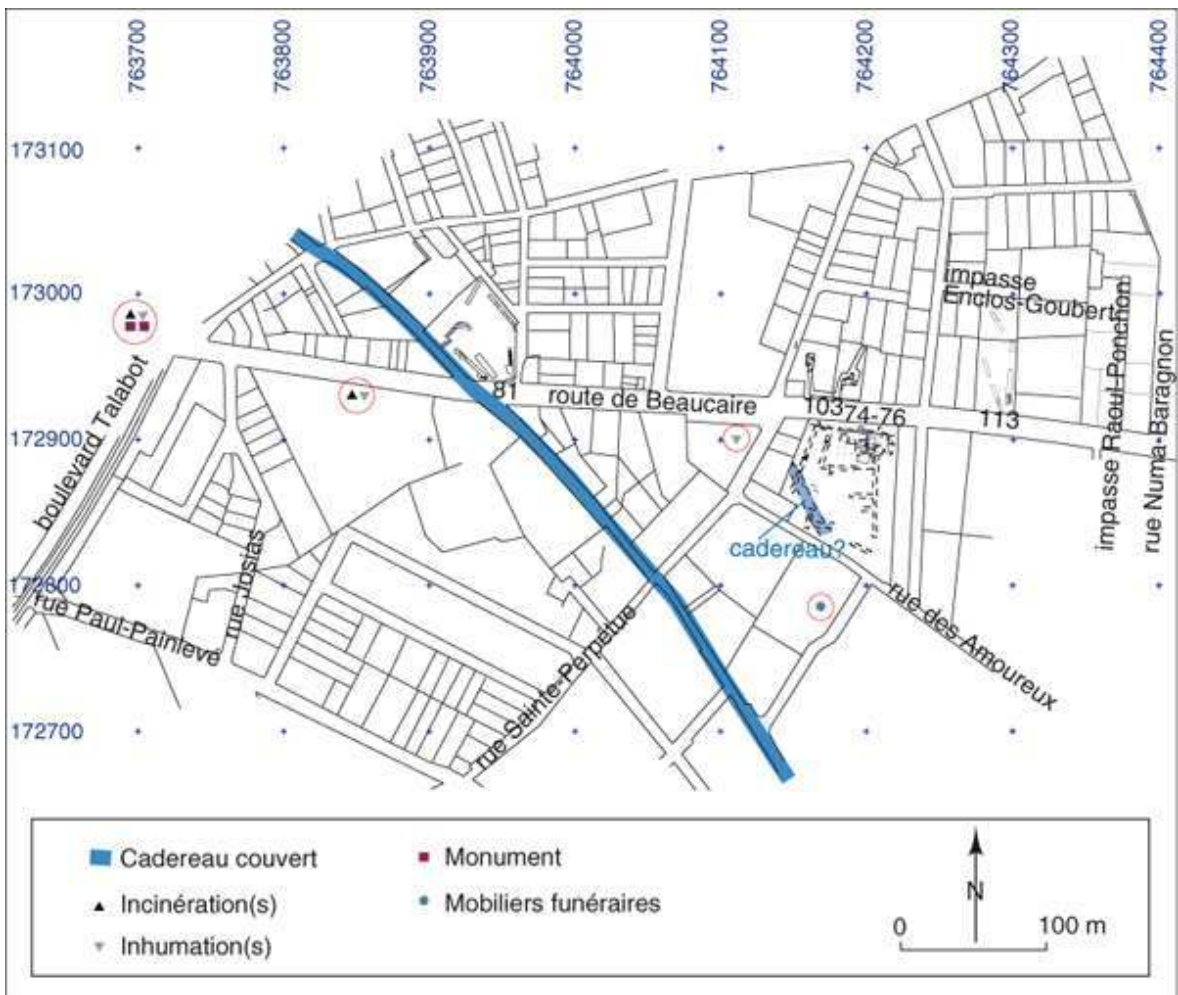

Auteur(s) : Vidal, Laurent ; Bel, Valérie ; Hervé, Marie-Laure ; Manniez, Yves ; Piskorz, Michel. Crédits ADLFI - Vidal Laurent (2004) 
Fig. $n^{\circ} 2$ : Plan de détail des vestiges du 103 , route de Beaucaire

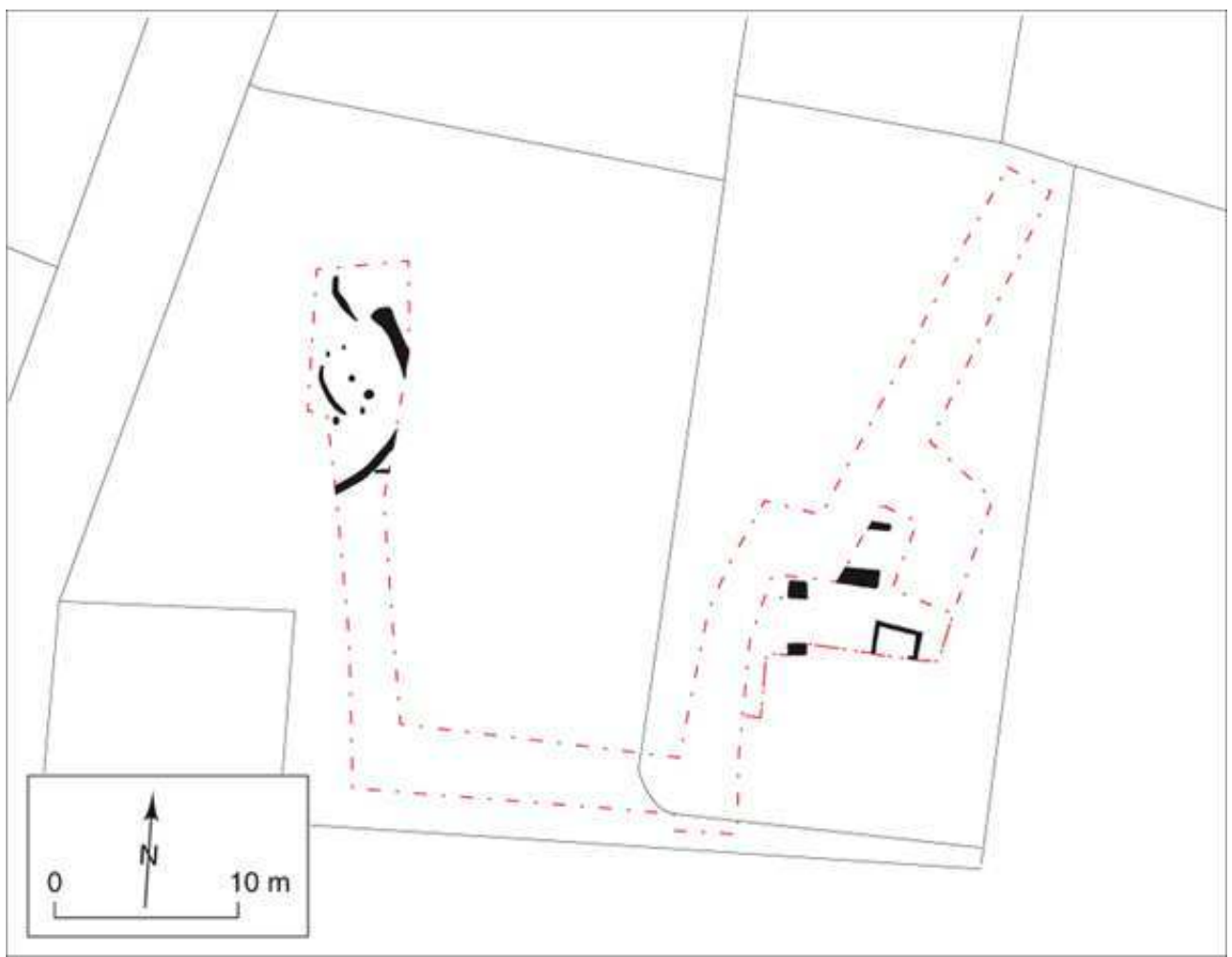

Auteur(s) : Hervé, Marie-Laure ; Vidal, Laurent. Crédits : ADLFI - Hervé Marie-Laure, Vidal Laurent (2004) 


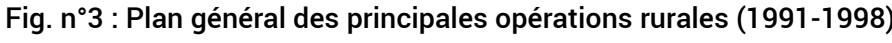

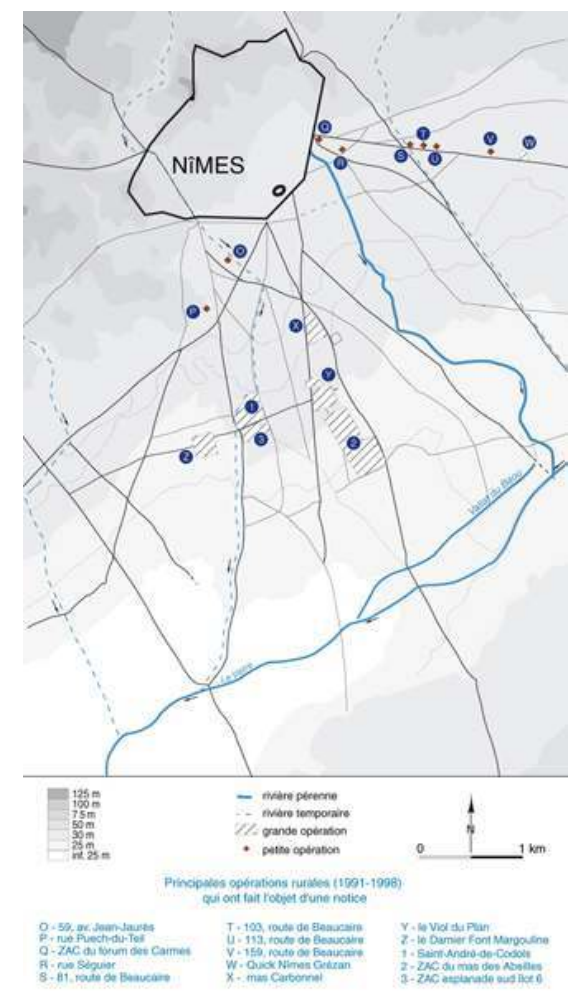

Auteur(s) : Vidal, Laurent. Crédits : ADLFI - Vidal, Laurent (2004)

INDEX

Index chronologique : Haut-Empire

Index géographique : Languedoc-Roussillon, Gard, Nîmes

operation sondage (SD)

\section{AUTEURS}

\section{MARIE-LAURE HERVÉ}

AFAN 